\title{
Marine Hybrid Power Drive System Based on Model Predictive Control
}

\author{
Huaqiang Zhang ${ }^{1}$, Fengming Sun ${ }^{1}$, Tong Yao $^{1}$,Xinsheng Wang ${ }^{1}$, Xiujing Qin ${ }^{1}$ \\ 1. Department of Electrical Engineering, \\ Harbin Institute of Technology at Weihai, \\ Weihai Shandong 264209, China;
}

\begin{abstract}
Ship hybrid power drive is an energy saving ship power scheme, the redundant mechanical energy of the diesel main engine can be converted into electricity by the shaft motor. However, the stator current and electromagnetic torque of shaft motor have obvious pulsation, which leads to the instability of ship electrical power system. In this paper, the model predictive direct power and torque control (MP-DPTC) for back-to-back inverter is proposed based on the switch table direct power and torque control (ST-DPTC). The optimal voltage vector and optimal duty cycle can effectively reduce the pulsation of the stator current and electromagnetic torque, so the cost function is established to calculate them. The simulation results show the proposed method can effectively eliminate the pulsation of the stator current and electromagnetic torque. Finally, the MP-DPTC was tested on a ship hybrid power experiment platform, and the surface-mounted permanent magnet synchronous motor is used as the shaft belt motor. The experimental results show pulsation of stator current and electromagnetic torque can be effectively eliminate when the shaft motor operates in the power generation or electric mod. The system achieves two-way flow of energy and has good static performance.
\end{abstract}

Key words: Hybrid power drive, energy feedback, model prediction control, optimal vector and duty cycle

\section{INTRODUCTION}

With the onset of the oil crisis and the rise in international fuel prices, the requirements for energy saving of the marine power systems are becoming increasingly higher. The ship power types include mechanical propulsion and electric propulsion. For the mechanical propulsion ship, the propulsion engines (gas turbines or diesel engines, etc.) directly drive the propeller through the shaft to power the ship. Due to the independence of the ship power and electric system, the fuel utilization rate is low. By contrast, the electric propulsion ships drive the motor via a frequency converter, and then the motor drives the propeller to power the ship. The operating efficiency and the energy efficiency are high due to the frequency drive method ${ }^{(1),(2)}$. However, the cost of electric propulsion is high, and the capacity of the electric equipment is limited. The marine hybrid drive system has emerged owing to this situation, which combines the advantages of mechanical propulsion and electric propulsion. This system is composed of a marine shaft power generation system, reversible frequency conversion shaft motor, four-quadrant converter, propeller device, gearbox, clutch, marine power station and diesel engine unit. Because the four-quadrant converter can realise the two-way flow of energy, the system can meet multiple speed requirements. In the course of high-speed voyage, the propulsion host and the shaft motor propel jointly provide the maximum propulsion power to the ship. In the course of low-speed voyage, the shaft motor is used separately to drive the ship. In the course of mid-speed voyage, the shaft motor runs in the state of power generation to absorb the redundant power of the propulsion engine, in which the grid-connected operation is achieved through the grid-side converter ${ }^{(3)}$.

In order to ensure the grid stability, the early marine hybrid drive system uses the synchronous compensator to provide the reactive power compensation, which has high cost and large space. And then the power compensation shaft motor systems use the high-power thyristor converter 
device; but the system harmonic content and power factor are not ideal. In this situation, the dual PWM back-to-back inverter is applied to the marine hybrid drive system, which effectively improves the stability of the ship's power $\operatorname{grid}^{(4),(5)}$. The traditional control strategy of the marine hybrid drive system includes the voltage vector directional control and the direct power torque control, the former has complex control algorithms and computations, and the latter significantly trembles during torque, active power and reactive power ${ }^{(6)}$. In order to improve the system performance, (6) proposed a complex vector PI regulator for the the dual PWM back-to-back inverter. Additionally, (3) proposed a variable frequency PWM rectifier scheme, which includes an inner current loop based on a complex vector PI controller and an outer voltage loop based on the instantaneous power balance. The method above renders a system that is robust to the frequency resonance transform. In addition to this, the new control strategies such as the sliding mode control and neural network control have the characteristics of fast tracking and anti-interference, which effectively improves the performance of the shaft belt motor system $^{(7)-(9)}$. Based on the switch table direct power and torque control (ST-DPTC), this paper proposes the model predictive direct power and torque control (MP-DPTC), which effectively reduces the current ripple and torque ripple of the system, as well as improves the stability and robustness of the system.

\section{THE MATHEMATICAL MODLE OF BACK-TO-BACK INVERTER}

\section{A. The Mathematical Model of Voltage Source Rectifier}

The grid side of the back-to-back inverter adopts the three-phase voltage source PWM rectifier (VSR) which conducts rectifier function, and the voltage source inverter (VSI) is used to drive the Permanent Magnet Synchronous Motor (PMSM) in the machine side.(The functions of VSR and VSI are interchanged to achieve energy feedback when the PMSM is working in the state of power generation) Fig. 1 shows the topology of the back-to-back inverter $^{(10)}$.

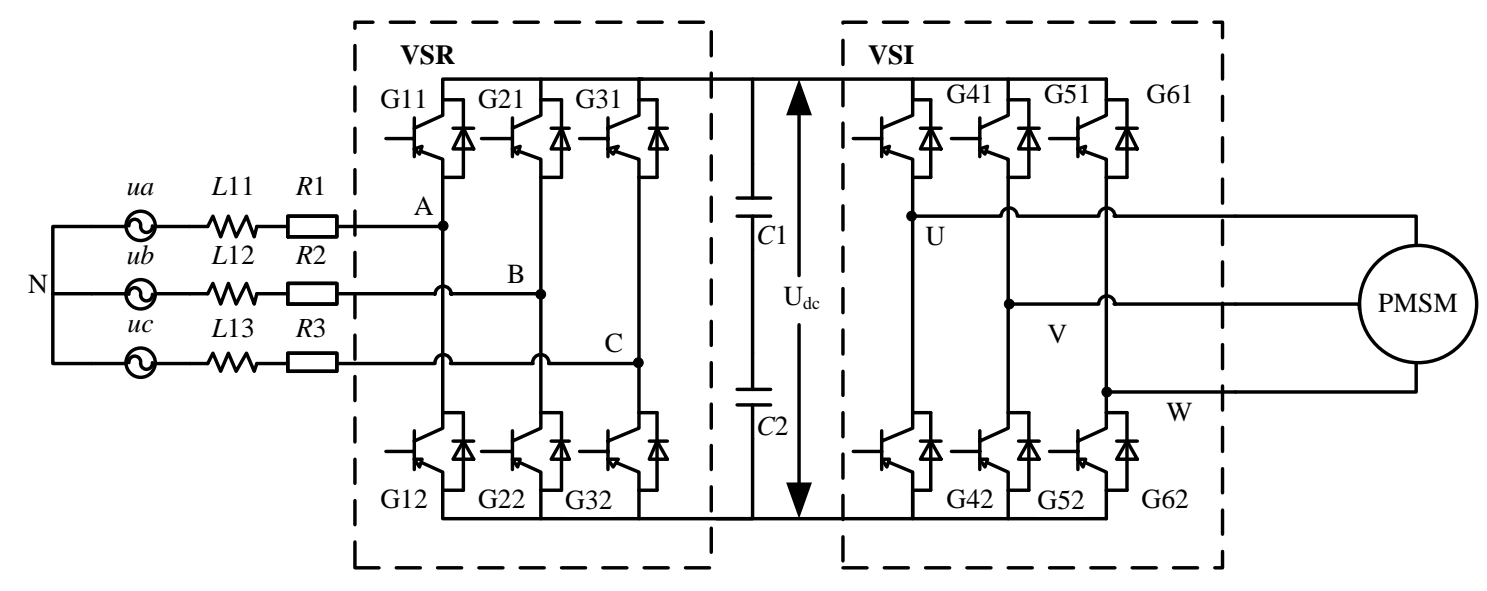

Fig. 1. The topology of back-to-back inverter

The circuit of a three-phase ac/dc converter studied in this paper is illustrated in Fig. 1 and its mathematical model in two phase stationary $\alpha-\beta$ frame is expressed as:

$$
\boldsymbol{u}=R \boldsymbol{i}+L \frac{d \boldsymbol{i}}{d t}+\boldsymbol{u}_{V S R}
$$

where $\mathbf{u}_{\mathrm{VSR}}, \mathbf{u}$, and $\mathbf{i}$ are rectifier voltage vector, grid voltage vector, and grid current vector, respectively; $\mathrm{R}$ and $\mathrm{L}$ are the equivalent series resistance and inductance of grid filter. The complex power is introduced in order to immediately control the active and reactive powers. The complex power $S$ at the grid side can be calculated from instantaneous theory as:

$$
\boldsymbol{S}=p+j q=\frac{3}{2}(\boldsymbol{i} * \boldsymbol{u})
$$

where $\mathbf{i}^{*}$ is the conjugate complex number of $\mathbf{i}, \mathrm{p}$ and $\mathrm{q}$ represent the active power and reactive power, respectively. The following equations holds true for balanced three-phase grid voltages:

$$
\frac{d \boldsymbol{u}}{d t}=j \omega|\boldsymbol{u}| e^{j \omega t}
$$

where $\omega$ is the grid frequency, $|\mathbf{u}|$ is the modulus of the grid voltage vector, The differentiation of grid current can be obtained from (1) as 


$$
\frac{d i}{d t}=\frac{1}{L}\left(\boldsymbol{u}-R \boldsymbol{i}-\boldsymbol{u}_{V S R}\right)
$$

From (2) to (4), the differentiation of complex power $S$ can be obtained as:

$$
\begin{aligned}
\frac{d \boldsymbol{S}}{d t} & =\frac{3}{2}\left(\frac{d \boldsymbol{u}}{d t} \boldsymbol{i}^{*}+\frac{d \boldsymbol{i}^{*}}{d t} \boldsymbol{u}\right) \\
& =\frac{3}{2}\left[\frac{1}{L}\left(\boldsymbol{u}^{*}-\boldsymbol{u}_{V S R}^{*}-R \boldsymbol{i}^{*}\right) \boldsymbol{u}+\boldsymbol{i}^{*} j \omega \boldsymbol{u}\right] \\
& =\frac{\frac{3}{2}\left(|\boldsymbol{u}|^{2}-\boldsymbol{u}_{V S R}^{*} \boldsymbol{u}\right)-(R-j \omega L) \boldsymbol{S}}{L}
\end{aligned}
$$

\section{B. The Mathematical Model of PMSM}

These assumptions are listed to facilitate the analysis:

1) Ignore the eddy current effect and hysteresis effect of motor.

2) Ignore the effect of the magnetic saturation.

3) The three-phase stator winding is symmetrical and there are 120 electrical angle differences between two adjacent winding.

4) The magnetic field presents a sine distribution in the air gap between stator and rotor.

5) The permanent magnet in the rotor adopts the patch structure ,furthermore, the distribution of the magnetic circuit is symmetrical.

Under the three-phase stationary coordinate system, the mathematical model of PMSM is nonlinear and close coupling. After transforming the mathematical model by Clark and Park transforms, the $\mathrm{dq}$ axis mathematical model of PMSM can be obtained ${ }^{(11),(12)}$.

The motor voltage equation are as follows:

$$
\left\{\begin{array}{l}
u_{\mathrm{sd}}=R_{\mathrm{s}} i_{\mathrm{sd}}+\frac{\mathrm{d} \psi_{\mathrm{sd}}}{\mathrm{d} t}-\omega_{\mathrm{r}} \psi_{\mathrm{sq}} \\
u_{\mathrm{sq}}=R_{\mathrm{s}} i_{\mathrm{sq}}+\frac{\mathrm{d} \psi_{\mathrm{sq}}}{\mathrm{d} t}+\omega_{\mathrm{r}} \psi_{\mathrm{sd}}
\end{array}\right.
$$

where $R_{s}$ is stator resistance, $n_{p}$ is pole pairs, $L_{d}, L_{q}$ are stator inductance dq axis component respectively. Motor is patch type. Thus, $\mathrm{L}_{\mathrm{d}}$ is equal to $\mathrm{L}_{\mathrm{q}}$. The electromagnetic torque equation is as follows:

$$
T_{e}=\frac{2}{3} n_{\mathrm{p}} \psi_{\mathrm{f}} i_{\mathrm{sq}}
$$

The stator flux equation are as follows:

$$
\left\{\begin{array}{l}
\psi_{\mathrm{sd}}=L_{\mathrm{d}} i_{\mathrm{sd}}+\psi_{f} \\
\psi_{\mathrm{sq}}=L_{\mathrm{q}} i_{\mathrm{sq}}
\end{array}\right.
$$

The Motor movement equation is as follows:

$$
T_{\mathrm{e}}-T_{\mathrm{L}}=J \frac{\mathrm{d} \Omega_{\mathrm{r}}}{\mathrm{d} t}+R_{\Omega} \Omega_{\mathrm{r}}
$$

where $\Psi_{\text {sd }}, \Psi_{\text {sq }}$ are stator flux dq axis component respectively, $i_{\text {sd }}, i_{\text {sq }}$ are stator current dq axis component respectively, $T_{L}$ is motor load torque, $T_{e}$ is motor electromagnetic torque, $\mathrm{J}$ is motor inertia, $\Omega_{\mathrm{r}}$ is motor rotor mechanical angular velocity, $\omega_{\mathrm{r}}$ is electrical motor speed, $\mathrm{R}_{\Omega}$ is damping coefficient.

\section{THE CONTROL STRATEGY OF BACK-TO-BACK INVERTER}

\section{A. The difference between the two control strategies}

The traditional back-to-back inverter adopts the ST-DPTC, which selects the voltage vector through the hysteresis comparator state and location of the magnetic chain, and the voltage vector of the ST-DPTC is discontinuous. Therefore, the insulated-gate bipolar transistor (IGBT) switching frequency is not fixed and this phenomenon leads to performance deterioration in switching losses, active power pulsations, and the total harmonic distortion (THD) of the grid-side current ${ }^{(13),(14)}$. In order to solve the problems existing in traditional controllers, MP-DPTC is proposed in this section. Based on the figure 2 , the voltage vectors is selected based on the hysteresis comparator and switch table in the traditional control strategy, which cannot match the system state very well. As well as the hysteresis also causes a certain error in the switching of the voltage vector. In contrast, the voltage vector is selected by the cost function in the improved control strategy, which can better match the system state, and the system runs more smoothly. In the model predictive direct power control (MP-DPC), the selection method of optimal voltage vector is proposed to optimize the vectors selection. On the other hand, in the model predictive direct torque control (MP-DTC), the selection method of optimal duty cycle is proposed to select an appropriate operating time of the optimal voltage vector $^{(15),(16)}$. All these methods ensure the stability of the system. 


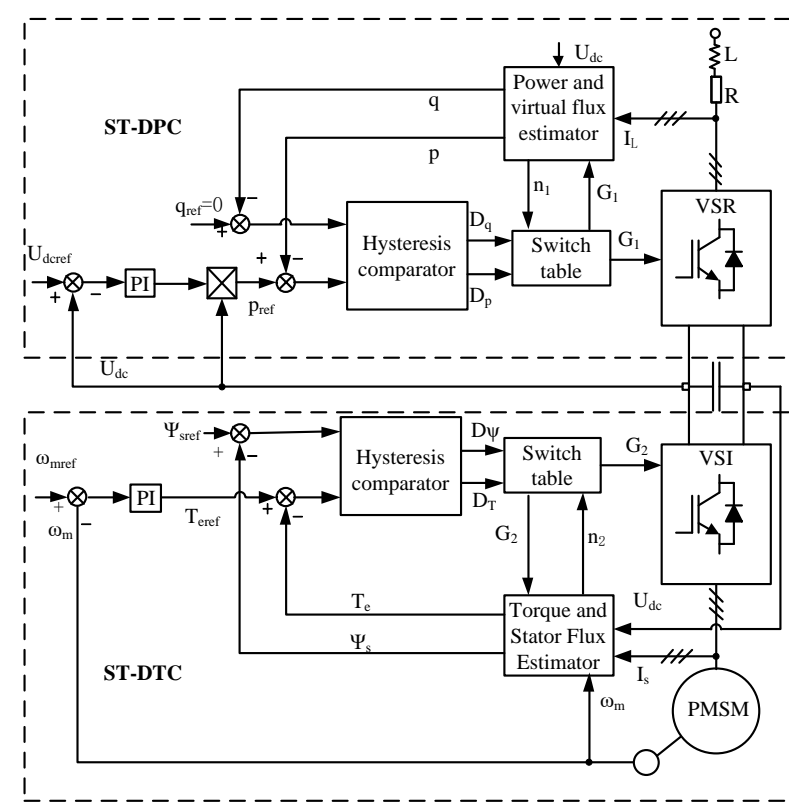

(a) The structure of the ST-DPTC

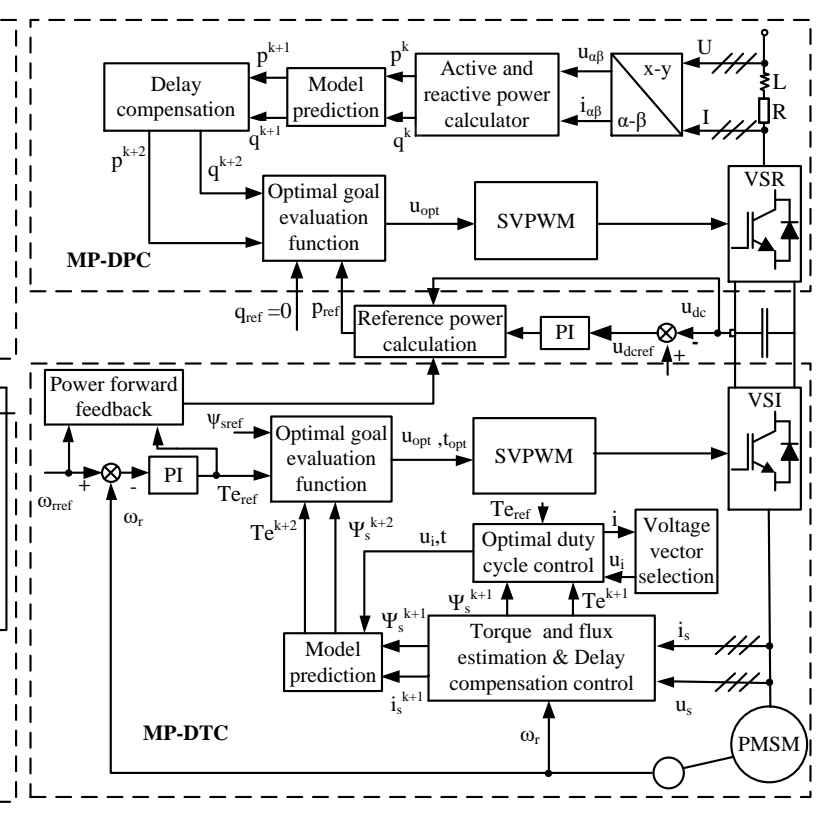

(b) The structure of the MP-DPTC

Fig. 2. The structure of control strategy

\section{B. The Optimal Voltage Vector of Model Predictive Direct}

\section{Power Control}

In model predictive direct power control(MP-DPC), the minimum power error is the basis for voltage vector selection in the next control period, so the cost function is set which takes both the power errors and selection of each voltage vector. And the optimal voltage vector is applied in the next control period which has the minimum cost result. Due to the control input of the system is finite, and combined with the characteristics of the finite control set model predictive control(FCS-MPC), the cost function and the predictive model are as follows:

$$
\begin{aligned}
g_{1} & =\left|S_{r e}^{k+1}-S^{k+1}\right|^{2}=\left|S_{r e f}^{k+1}-S^{k}-\Delta S^{k+1}\right|^{2} \\
& =\left(p_{r e f}^{k+1}-p^{k+1}\right)^{2}+\left(q^{k+1}\right)^{2}
\end{aligned}
$$

The $(\mathrm{k})$ or $(\mathrm{k}+1)$ in the superscript represents the sampled value of the parameter at $(\mathrm{k})$ th or $(\mathrm{k}+1) \mathrm{th}, \Delta S^{\mathrm{k}+1}$ is the change in complex power at $(k+1)$ th. The complex power at $(k+1)$ th instant should be predicted for the aim of cost function evaluation for each voltage vector. By decomposing the real and imaginary components of Equation (9), the differentiations of active and reactive powers are as follows:

$$
\left[\begin{array}{c}
\frac{d p}{d t} \\
\frac{d q}{d t}
\end{array}\right]=\frac{3}{2 L}\left[\begin{array}{c}
|\boldsymbol{u}|^{2}-\operatorname{Re}\left(\boldsymbol{u}_{V S R}^{*} \boldsymbol{u}\right) \\
-\operatorname{Im}\left(\boldsymbol{u}_{V S R}^{*} \boldsymbol{u}\right)
\end{array}\right]-\frac{R}{L}\left[\begin{array}{l}
p \\
q
\end{array}\right]+\omega\left[\begin{array}{c}
-q \\
p
\end{array}\right]
$$

From Equation (9), the prediction of $\mathrm{p}$ and $\mathrm{q}$ at $(\mathrm{k}+$ 1)th can be obtained as

$$
\begin{aligned}
{\left[\begin{array}{c}
p^{k+1} \\
q^{k+1}
\end{array}\right]=} & {\left[\begin{array}{c}
p^{k} \\
q^{k}
\end{array}\right]+\frac{3 T_{S}}{2 L}\left[\begin{array}{c}
\left|\boldsymbol{u}^{k}\right|-\operatorname{Re}\left(\operatorname{conj}\left(\boldsymbol{u}_{V S R}^{k}\right) \boldsymbol{u}^{k}\right) \\
-\operatorname{Im}\left(\operatorname{conj}\left(\boldsymbol{u}_{V S R}^{k}\right) \boldsymbol{u}^{k}\right)
\end{array}\right] } \\
& -\frac{R T_{S}}{L}\left[\begin{array}{c}
p^{k} \\
q^{k}
\end{array}\right]+\omega T_{S}\left[\begin{array}{c}
-q^{k} \\
p^{k}
\end{array}\right]
\end{aligned}
$$

The formula of the active power and reactive power at (k)th are as follows:

$$
\left[\begin{array}{l}
p^{k} \\
q^{k}
\end{array}\right]=\frac{3}{2}\left[\begin{array}{ll}
u_{\alpha}^{k} & u_{\beta}^{k} \\
u_{\beta}^{k} & -u_{\alpha}^{k}
\end{array}\right]\left[\begin{array}{c}
i_{\alpha}^{k} \\
i_{\beta}^{k}
\end{array}\right]
$$

where $u_{\alpha}, u_{\beta}$ are grid voltage $\alpha \beta$ axis component respectively, $i_{\alpha}, i_{\beta}$ are grid current $\alpha \beta$ axis component respectively. Based on the Equation (10), the selection is cumbersome, which needs to check the voltage vector one by one. To simplify the process of vector selection, an optimal voltage vector selection method is described in this section. In the process of vector selection by Equation (10), it is found that the $\Delta S^{k+1}$ is the most complicated part. Combined with the Equation (5), $\Delta S^{k+1}$ includes the time-varying parameter $\mathbf{u}^{*}{ }_{\text {VSR }}$ and $\mathbf{u}$, which increases the complexity of the vector selection. Where $\mathbf{u}^{*}$ VSR is the conjugate coefficient of converter voltage and $\mathbf{u}$ is the grid voltage vector. In order to get the optimal voltage vector faster, the way of the vector selection will be transformed to an appropriate coordinate system ${ }^{(17)}$. In synchronous dq 
coordinate system with the d-axis attached to the position of grid voltage vector, the grid voltage becomes $\left|\mathbf{u}_{\mathrm{dq}}\right|=|\mathbf{u}|=\mathrm{U}$, where $\mathrm{U}$ is the amplitude of grid voltage vector. Firstly, the time-varying term in Equation (5) can be eliminated in dq coordinate system, the new equation is as follows:

$$
\frac{d \boldsymbol{S}_{\mathrm{dq}}}{d t}=\frac{\frac{3}{2}\left(U^{2}-\boldsymbol{u}_{\mathrm{VSR}_{\mathrm{dq}}}^{*} U\right)-(R-j \omega L) \boldsymbol{S}_{\mathrm{dq}}}{L}
$$

where $\boldsymbol{u}_{V S R_{d q}}^{*}$ is the conjugate rectifier voltage vector in synchronous $\mathrm{dq}$ frame. It can be obtained from the conjugate rectifiers voltage vector $\boldsymbol{u}_{V S R}^{*}$ in stationary frame using Park transformation as follows:

$$
\boldsymbol{u}_{V S R_{d q}}^{*}=\boldsymbol{u}_{V S R}^{*} \cdot \mathrm{e}^{-j \theta}
$$

where $\theta=\angle \mathbf{u}$ is the angle of grid voltage vector. After discretization processing, the new dq-axis mathematical equation of the complex power is as follows:

$$
\boldsymbol{S}_{\mathrm{dq}}^{\mathrm{k}+1}=\boldsymbol{S}_{\mathrm{dq}}^{\mathrm{k}}+\frac{\left[\frac{3}{2}\left(U^{2}-\boldsymbol{u}_{\mathrm{VSR}_{\mathrm{dq}}}^{*} U\right)-(R-j \omega L) \boldsymbol{S}_{\mathrm{dq}}^{\mathrm{k}}\right] T_{\mathrm{s}}}{L}
$$

According to Equation (12) and the characteristics of the effective and zero voltage vectors, the influence of the zero vector is expressed as $S_{\mathrm{dq}}^{\mathrm{k}}+\frac{\left[\frac{3}{2} U^{2}-(R-j \omega L) S_{\mathrm{dq}}^{\mathrm{k}}\right] T_{\mathrm{s}}}{L}=\boldsymbol{X}_{0,7}^{\mathrm{k}}$ and the influence of the effective vector is expressed as $\frac{3 U T_{S}}{2} \boldsymbol{u}_{V S R_{d_{q}}}^{*}$. Thus, the mathematical equation of the complex power at $(\mathrm{k}+1)$ th is as follows:

$$
\begin{aligned}
\varepsilon\left(\boldsymbol{S}_{d q}^{k+1}\right) & =\boldsymbol{S}_{d q_{r e f}}^{k+1}-\boldsymbol{S}_{d q}^{k+1} \\
& =\boldsymbol{S}_{d q_{r e f}}^{k+1}-\boldsymbol{X}_{0,7}^{k+1}+\frac{3 U T_{s}}{2 L} \boldsymbol{u}_{V S R_{d q}}^{*} \\
& =\varepsilon\left(\boldsymbol{X}_{0,7}^{k+1}\right)+\frac{3 U T_{s}}{2 L} \boldsymbol{u}_{V S R_{d q}}^{*}
\end{aligned}
$$

Fig. 3 shows the selection method of voltage vector. $\boldsymbol{b}=\boldsymbol{X}_{0,7}^{(k+1)}-\boldsymbol{S}_{d q r e f}^{(k+1)}=-\varepsilon\left(\boldsymbol{X}_{0,7}^{k+1}\right)$ is in the sector shown in Fig. 3, where $\boldsymbol{\alpha}$ is the influence of the effective voltage vector, $\mathbf{c}$ and $\mathbf{d}$ respectively represent the complex power error of the effective voltages $\mathbf{v}_{6}$ and $\mathbf{v}_{1}$.

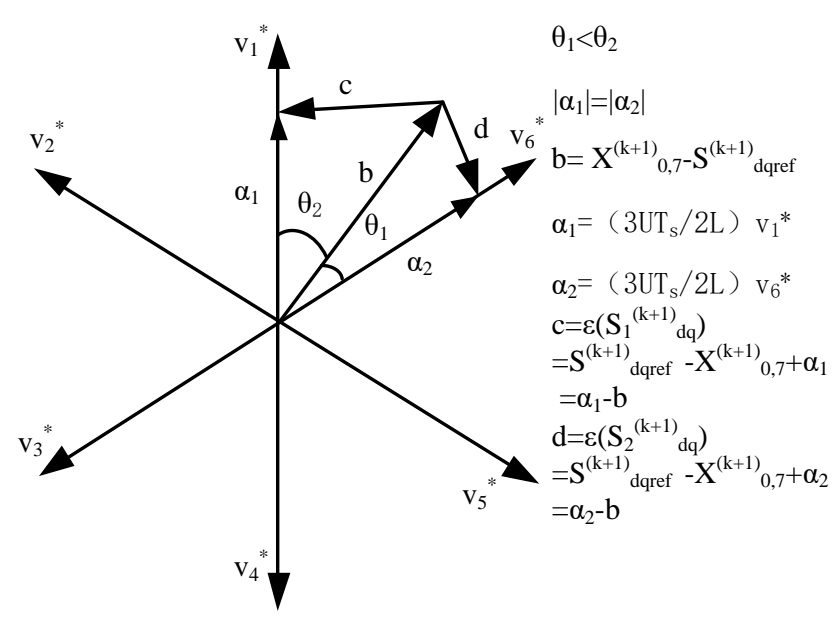

Fig. 3. Voltage vector selection method

According to the formula in Fig. 3, $\left|\boldsymbol{\alpha}_{1}\right|$ is equal to $\left|\boldsymbol{\alpha}_{2}\right|$ because of $\left|\mathbf{v}_{1}{ }^{*}\right|$ is equal to $\left|\mathbf{v}_{6}{ }^{*}\right|$, the complex power error $\mathbf{c}$ and $\mathbf{d}$ can be calculated base on the Equation (17): $\mathbf{c}=\boldsymbol{\alpha}_{1}-\mathbf{b}, \mathbf{d}=\boldsymbol{\alpha}_{2}-\mathbf{b}$. The size of $\mathrm{c}$ and $\mathrm{d}$ can be obtained by the cosine theorem: $\quad|\mathbf{c}|^{2}=\left|\boldsymbol{\alpha}_{1}\right|^{2}+|\mathbf{b}|^{2}-2\left|\boldsymbol{\alpha}_{1}\right||\mathbf{b}| \cos \theta_{2}$, $|\mathbf{d}|^{2}=\left|\boldsymbol{\alpha}_{2}\right|^{2}+|\mathbf{b}|^{2}-2\left|\boldsymbol{\alpha}_{2}\right||\mathbf{b}| \cos \theta_{1}$ and $\theta_{1}>\theta_{1}$. Clearly, $|\mathbf{d}|<|\mathbf{c}|$, and $\mathbf{v}_{6}$ is more suitable than $\mathbf{v}_{1}$ in Fig. 3. This selection process is much simpler than searching the optimal voltage vector one by one. Thus, the cost function of the optimal voltage vector is as follows:

$$
g_{1}=\left|S_{r e f}^{k+1}-S^{k+1}\right|^{2}=\left|S_{d q_{r e f}}^{k+1}-S_{d q}^{k+1}\right|^{2}
$$

Under ideal conditions, the controller exerts the grid voltage vector at the $\mathrm{k}$ moment, subsequently, the active and reactive powers can quickly reach the given value at $(\mathrm{k}+1)$ th. Owing to the system hysteresis, the control reaches the given value at $(\mathrm{k}+2)$ th, clearly, the system lag time has to be compensated ${ }^{(18)}$. Thus, the improved EF of the optimal voltage vector is as follows:

$$
g_{1}=\left|S_{r e f}^{k+2}-S^{k+2}\right|^{2}=\left|S_{d q_{r e f}}^{k+2}-S_{d q}^{k+2}\right|^{2}
$$

Based on the model prediction, the MP-DPC controls the active and reactive powers in real time during each sampling period in order to control the grid current. For a minimum error, cost function is set to obtain the optimal voltage vector, so that the system can quickly control the rectifier to meet the dynamic performance index.

C. The Optimal Duty Cycle of Model Predictive Direct Torque Control 
Fig. 3 shows that the model predictive direct torque control (MP-DTC) is adopted by the inverter. According to the characteristics of the system, the system prediction model and cost function are established based on FCS-MPC. Firstly, the PMSM mathematical model in synchronous dq frame is known, by the Park inverse transformation, the formula of stator flux and electromagnetic torque at $(\mathrm{k})$ th are as follows:

$$
\begin{aligned}
{\left[\begin{array}{c}
\psi_{s \alpha}^{k} \\
\psi_{s \beta}^{k}
\end{array}\right] } & =\left[\begin{array}{l}
\int_{0}^{k}\left(u_{s \alpha}-R_{s} i_{s \alpha}\right) d t+\psi_{s \alpha}^{0} \\
\int_{0}^{k}\left(u_{s \beta}-R_{s} i_{s \beta}\right) d t+\psi_{s \beta}^{0}
\end{array}\right] \\
T_{e}^{k} & =\frac{3}{2} n_{p}\left(\psi_{s \alpha}^{k} i_{s \beta}^{k}-\psi_{s \beta}^{k} i_{s \alpha}^{k}\right)
\end{aligned}
$$

Subsequently, the prediction model of the stator flux is obtained by discretization of the motor voltage formula in stationary $\alpha \beta$ frame.

$$
\left[\begin{array}{c}
\psi_{s \alpha}^{k+1} \\
\psi_{s \beta}^{k+1}
\end{array}\right]=\left[\begin{array}{c}
\psi_{s \alpha}^{k} \\
\psi_{s \beta}^{k}
\end{array}\right]+T_{s}\left[\begin{array}{c}
u_{s \alpha}^{k}-R_{s} i_{s \alpha}^{k} \\
u_{s \beta}^{k}-R_{s} i_{s \beta}^{k}
\end{array}\right]
$$

The predicted value of stator current is necessary to the torque prediction model. According to Equation (6) and (8), the prediction model of stator current in synchronous dq frame is as follows:

$$
\left[\begin{array}{c}
i_{s d}^{k+1} \\
i_{s q}^{k+1}
\end{array}\right]=\left[\begin{array}{c}
i_{s d}^{k} \\
i_{s q}^{k}
\end{array}\right]+\frac{T_{s}}{L_{d}}\left[\begin{array}{c}
u_{s d}^{k}+\omega_{r}^{k} L_{q} i_{s d}^{k}-R_{s} i_{s q}^{k} \\
u_{s q}^{k}-R_{s} i_{s q}^{k}-\omega_{r}^{k} L_{d} i_{s d}^{k}-\omega_{r}^{k} \psi_{f}
\end{array}\right]
$$

According to the Equation (23), the current predicted value in synchronous dq frame is obtained. Subsequently, the current predicted value is inverse Park transformed, combined with the predicted value of the stator flux, the prediction formula of the motor torque is as follows:

$$
T_{e}^{k+1}=\frac{3}{2} n_{\mathrm{p}}\left[\psi_{s \alpha}^{k+1} i_{s \beta}^{k+1}-\psi_{s \beta}^{k+1} i_{s \alpha}^{k+1}\right]
$$

Owing to the system hysteresis, the expected control effect is achieved at $(\mathrm{k}+2)$ th when the motor controller applies the stator voltage vector at $(\mathrm{k})$ th. Thus, the system requires a time delay compensation. The cost function of the optimal voltage vector is as follows:

$$
g_{2}=\left|T_{\mathrm{e}} \underset{\text { ref }}{\mathrm{k}+2}-T_{\mathrm{e}}^{\mathrm{k}+2}\right|^{2}+\eta^{2}\left|\psi_{\mathrm{sref}}^{\mathrm{k}+2}-\psi_{\mathrm{s}}^{\mathrm{k}+2}\right|^{2}
$$

where $T_{\mathrm{e}_{\mathrm{ref}}}^{\mathrm{k}+2}$ is the preset electromagnetic torque of the system at $(\mathrm{k}+2)$ th, $\psi_{\mathrm{s}_{\mathrm{ref}}}^{\mathrm{k}+2}$ is the preset stator flux of the system at $(\mathrm{k}+2) \mathrm{th}, \quad \eta=T_{\mathrm{en}} / \psi_{\mathrm{s}_{\mathrm{ref}}}$ represents the weight coefficient of stator flux and electromagnetic torque.

The torque ripple is the toughest challenge of the direct torque control, this is because the voltage vector remains constant in each sampling period. Although this problem can be improved by shortening the sampling time, the performance requirements of the power component are very high and the switching losses are larger. Therefore, the zero vector is introduced to match the action time of the optimal voltage vector to reduce the motor torque ripple. By combining the MP-DTC with the optimal duty cycle control, the action time of effective voltage vector can be controlled. The inverter outputs two voltage vectors in each sampling cycle. Under this premise, the zero vector mainly reduces the electromagnetic torque, however the effective voltage vector is used to increase the electromagnetic torque, so that the effective voltage vector needs to be selected specifically.

Table1. The switching lookup table

\begin{tabular}{|l|c|c|c|}
\hline \multirow{2}{*}{$\Psi_{\text {s }}$ in sector $\mathrm{i}$} & \multicolumn{2}{|c|}{$\mathrm{T}_{\mathrm{e}}$} \\
\cline { 2 - 4 } & $\uparrow$ & $\downarrow$ \\
\hline \multirow{3}{*}{$\Psi_{\mathrm{s}}$} & $\uparrow$ & $\mathrm{u}_{\mathrm{i}+1}$ & $\mathrm{u}_{0}, \mathrm{u}_{7}$ \\
\cline { 2 - 4 } & $\downarrow$ & $\mathrm{u}_{\mathrm{i}+2}$ & $\mathrm{u}_{0}, \mathrm{u}_{7}$ \\
\hline
\end{tabular}

The voltage vector selection table is as follows:In the Table1, where $\mathrm{i}$ is the stator flux sector position, the selection of effective voltage vectors form a cycle from $\mathbf{u}_{1}$ to $\mathrm{u}_{6}, \uparrow(\downarrow)$ indicates that the voltage vector can increase (reduce) the value of the corresponding item. To obtain the optimal duty cycle of the effective voltage vector, the mathematical model of the electromagnetic torque under the influence of the effective and zero voltage vectors must be constructed. According to this model, the minimum error between the actual value and the reference value of the electromagnetic torque in each sampling period must be ensured ${ }^{(19)}$. Through Equations (6), (7) and (8), the mathematical expression of electromagnetic torque under the influence of the effective voltage vector is as follows:

$$
\frac{\mathrm{d} T_{\mathrm{e}}}{\mathrm{d} t}=\frac{3 n_{\mathrm{p}}}{2 L_{\mathrm{d}}}\left(\operatorname{Im}\left(u_{\mathrm{s}} \psi_{\mathrm{f}}\right)-\frac{R_{\mathrm{s}}}{L_{\mathrm{d}}} \operatorname{Im}\left(\psi_{\mathrm{s}} \psi_{\mathrm{f}}\right)-\omega_{\mathrm{r}} \operatorname{Re}\left(\psi_{\mathrm{s}} \psi_{\mathrm{f}}\right)\right)
$$

Similarly, the mathematical expression of the electromagnetic torque under the influence of the zero voltage vector is as follows:

$$
\frac{\mathrm{d} T_{\mathrm{e}}}{\mathrm{d} t}=-\frac{3 n_{\mathrm{p}}}{2 L_{\mathrm{d}}}\left(\frac{R_{\mathrm{s}}}{L_{\mathrm{d}}} \operatorname{Im}\left(\psi_{\mathrm{s}} \psi_{\mathrm{f}}\right)+\omega_{\mathrm{r}} \operatorname{Re}\left(\psi_{\mathrm{s}} \psi_{\mathrm{f}}\right)\right)
$$


According to Equations (23) and (24), the mathematical expression of the electromagnetic torque under the influence of the voltage vector can be obtained. As $s_{1}$ is the rate of change under the effective voltage vector, $s_{2}$ is the rate of change under the zero voltage vector. In fact, the sampling time set by the experimental platform and the simulation is $5 \times 10^{-5} \mathrm{~s}$. As the sampling time of the system is very short, $s_{1}$ and $s_{2}$ can be considered constant. The evaluation method of the optimal duty cycle is shown in Fig. 4, where $t_{\mathrm{e}}$ is the instantaneous value of the electromagnetic torque in the whole process, and $\mathrm{Te}^{(\mathrm{k}+1)}$ is the electromagnetic torque obtained after the delay compensation, $\mathrm{S}_{1}, \mathrm{~S}_{2}$, and $\mathrm{S}_{3}$ are the area of shadow.

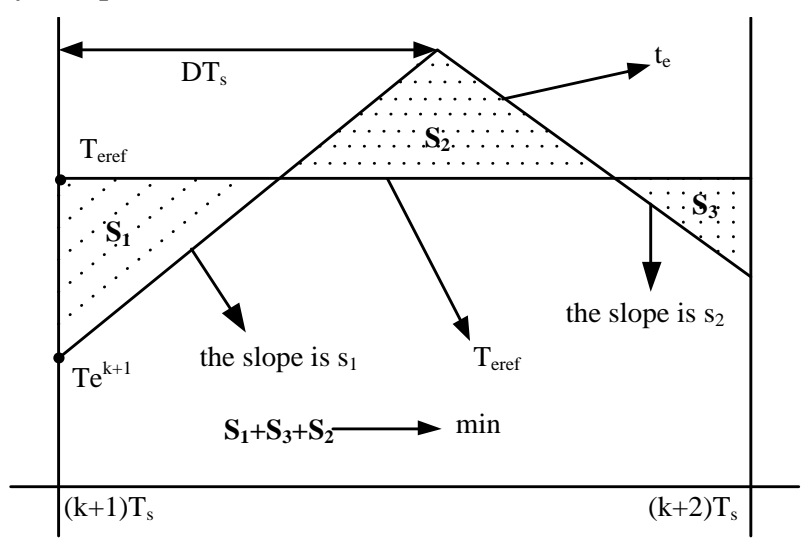

Fig. 4. The evaluation method of optimal duty cycle

In order to ensure the stable operation of the system, it is necessary to select an optimal duty cycle $\mathrm{D}$ to match the voltage vector. According to Fig. 4, the deviation degree of electromagnetic torque $t_{\mathrm{e}}$ from the given value $\mathrm{T}_{\text {eref }}$ can be expressed by the shadow in a sampling period. The shadow area formula is as follows:

$$
\begin{aligned}
\frac{1}{T_{\mathrm{s}}} \int_{(\mathrm{k}+1) T_{s}}^{(\mathrm{k}+2) T_{\mathrm{s}}}\left(t_{e}-T_{\mathrm{e}_{\mathrm{ref}}}\right)^{2} d t & =\frac{1}{T_{\mathrm{s}}}\left[\int_{(\mathrm{k}+1) T_{s}}^{(\mathrm{k}+D) T_{\mathrm{s}}}\left(t_{e}-T_{e}^{k+1}-s_{1} t\right)^{2} d t\right] \\
+ & \frac{1}{T_{\mathrm{s}}}\left[\int_{(\mathrm{k}+\mathrm{D}) T_{s}}^{(\mathrm{k}+2) T_{\mathrm{s}}}\left(t_{e}-T_{e}^{k+1}-s_{1} D-s_{2} t\right)^{2} d t\right]
\end{aligned}
$$

To reduce the electromagnetic torque ripple, the state when the integral value is minimum must be obtained, and then the optimal duty cycle is obtained. The derivative of integral value with respect to duty cycle D is set to zero ${ }^{(20)}$. According to the geometric relationship in the Fig. 5, the optimal duty cycle of the effective voltage is obtained:

$$
D=\frac{2\left(T_{\mathrm{e}_{\mathrm{ref}}}-T_{\mathrm{e}}^{\mathrm{k}+1}\right)}{\left(2 s_{1}-s_{2}\right) T_{\mathrm{s}}}-\frac{s_{2}}{2 s_{1}-s_{2}}
$$

By combining the MP-DTC algorithm with optimal duty cycle control, the system effectively reduces the torque ripple and improves the system stability.

\section{THE SIMULATION OF MP-DPTC}

In order to verify the correctness and validity of the MP-DPTC, the ST-DPTC and MP-DPTC are experimented respectively in Matlab environment. Table 2 shows the system parameters.

\begin{tabular}{|c|c|c|c|}
\multicolumn{5}{l}{ Table 2. PMSM Parameters } \\
\hline Parameter & Value & Parameter & Value \\
\hline Rated Power $P_{\mathrm{N}}$ & $5.5 \mathrm{~kW}$ & q-axis inductance $L_{\mathrm{q}}$ & $8.5 \mathrm{mH}$ \\
\hline Rated Speed $n_{\mathrm{N}}$ & $1500 \mathrm{r} / \mathrm{min}$ & d-axis inductance $L_{\mathrm{d}}$ & $8.5 \mathrm{mH}$ \\
\hline Rated Current $I_{\mathrm{N}}$ & $10 \mathrm{~A}$ & Permanent flux $\Psi_{\mathrm{f}}$ & $0.175 \mathrm{~Wb}$ \\
\hline Rated Voltage $U_{\mathrm{N}}$ & $380 \mathrm{~V}$ & Stator Resistance $R_{\mathrm{s}}$ & $2.875 \Omega$ \\
\hline Pole pairs $n_{\mathrm{p}}$ & 2 & Rotational Inertia $J$ & $0.045 \mathrm{~kg} \bullet \mathrm{m}^{2}$ \\
\hline
\end{tabular}

Setting the simulation conditions: the preset speed is equal to $1200 \mathrm{r} / \mathrm{min}$ before $0.3 \mathrm{~s}$, after that, the preset speed turn into $-800 \mathrm{r} / \mathrm{min}$ to realize the power generation operation of the system. Fig. 5 shows the simulation results of the speed, $\mathrm{U}_{\mathrm{dc}}$, active power, reactive power, electromagnetic torque, stator current and current harmonic analysis. Firstly, the system speed is stable about $0.05 \mathrm{~s}$, then the motor switches to the power generation mode at $0.3 \mathrm{~s}$, the speed has an instantaneous overshoot about $0.34 \mathrm{~s}$, finally the speed stable at $-800 \mathrm{r} / \mathrm{min}$. Based on the speed results, there is no significant difference in the speed control capability of the two control strategies. And then, both MP-DPTC and ST-DPTC ensure $\mathrm{U}_{\mathrm{dc}}$ stability in the two work modes in the result.

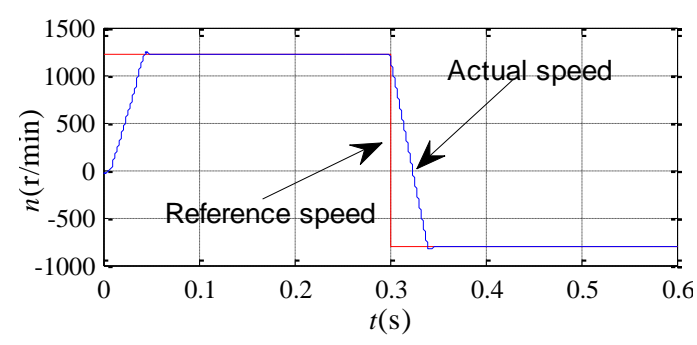

(a) The speed simulation of MP-DPTC

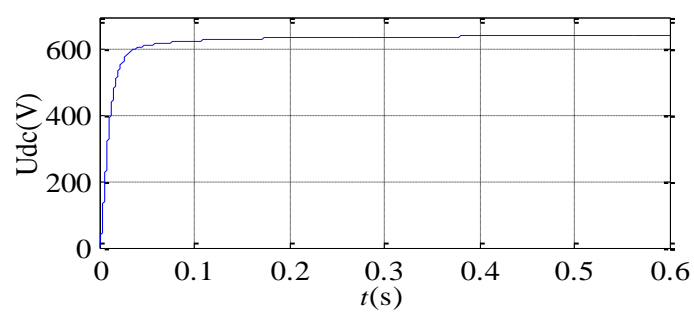

(b) the MP-DPTC $U_{\mathrm{dc}}$ 


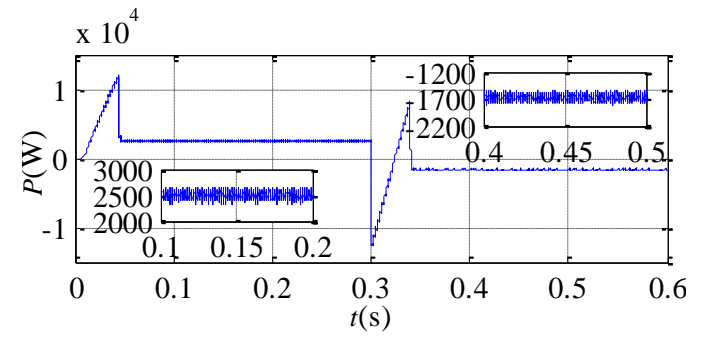

(c) the active power of MP-DPTC

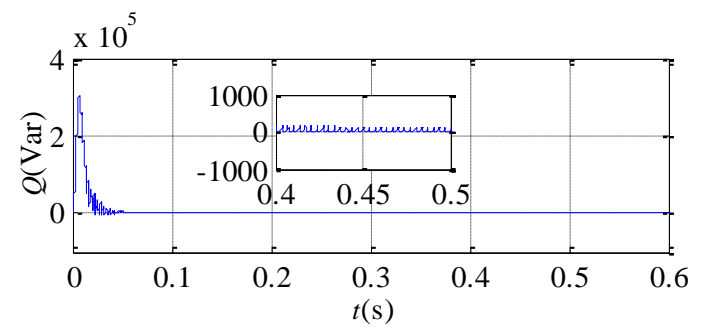

(d) the reactive power of MP-DPTC

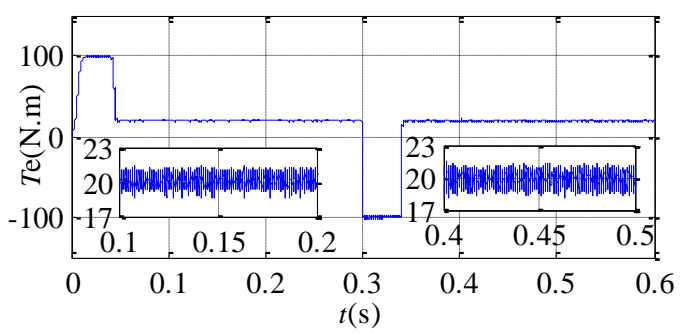

(e) The electromagnetic torque of MP-DPTC

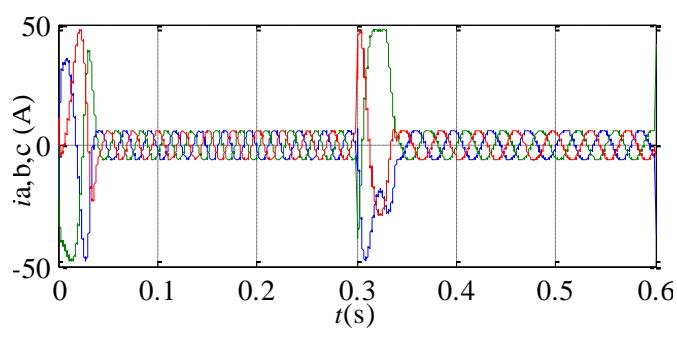

(f) The stator current of MP-DPTC

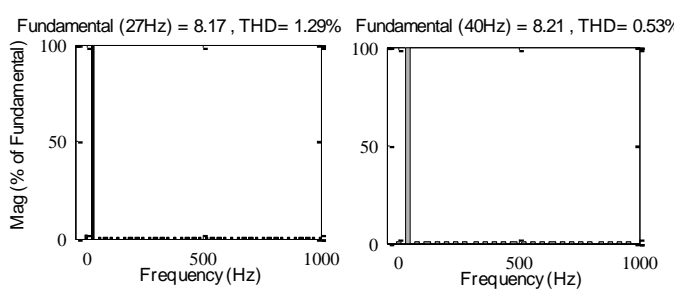

(g) The stator current of ST-DPTC

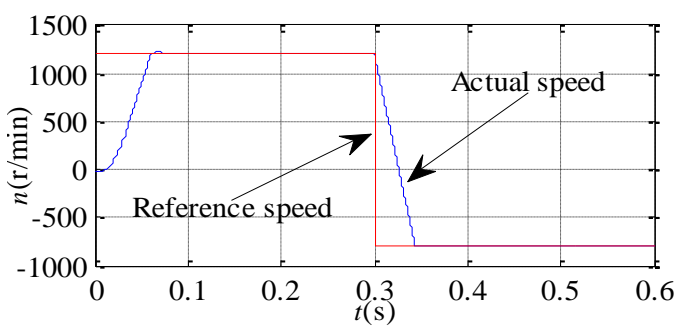

(h) the speed simulation of ST-DPTC

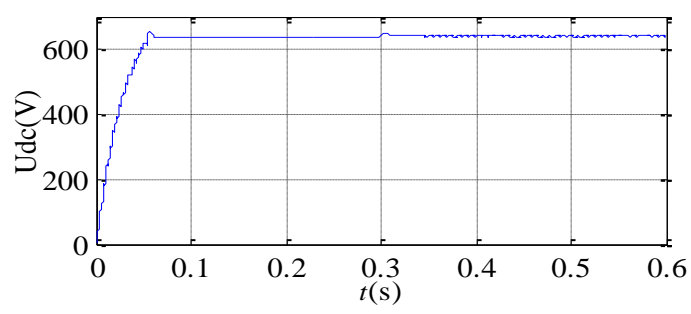

(i) the ST-DPTC $U_{d c}$

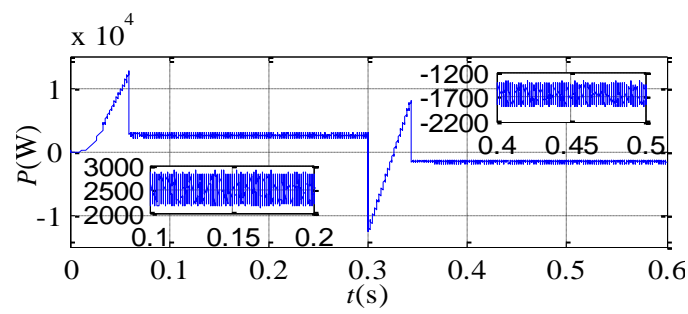

(j) the active power of ST-DPTC

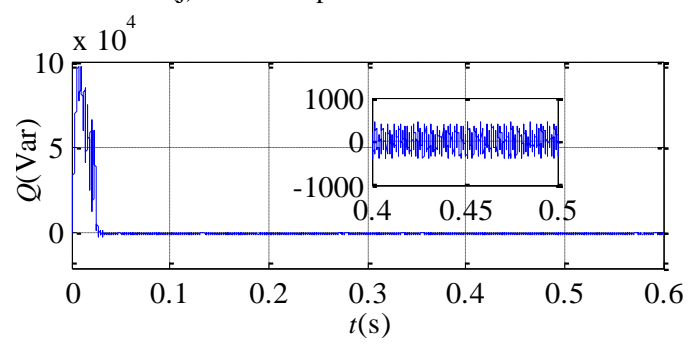

(k) the reactive power of ST-DPTC

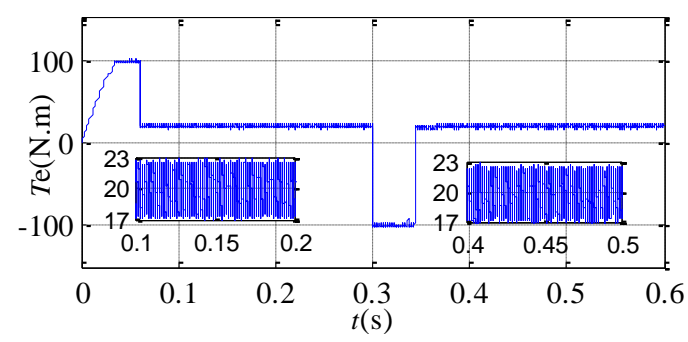

(1) The electromagnetic torque of ST-DPTC

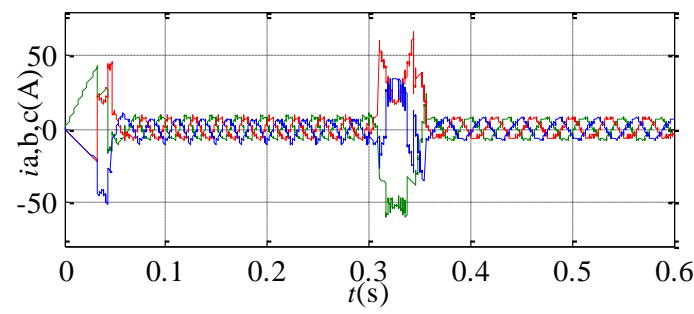

(m) The stator current of ST-DPTC

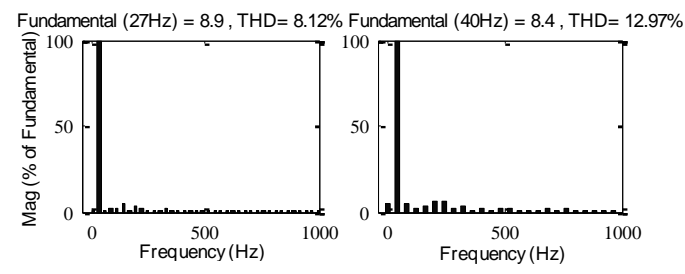

(n) The stator current of ST-DPTC

Fig.5 The simulink result of MP-DPTC and ST-DPTC 
According to Fig. 5, the simulation result of the active power, reactive power, electromagnetic torque, stator current and current harmonic is as follows: Firstly, the system status is stable about $0.05 \mathrm{~s}$, the active power of motor reaches to $2.5 \mathrm{~kW}$ and reactive power reaches to $0 \mathrm{Var}$, as well as the value of the electromagnetic torque is $20 \mathrm{~N} . \mathrm{m}$ at this time. Subsequently, the motor switches to the power generation mode when the time is $0.3 \mathrm{~s}$, the electromagnetic torque reaches the limit value and the system transits to steady state quickly. Finally, the state of the system reaches stability about $0.34 \mathrm{~s}$. At this point, the value of active power is $-1.7 \mathrm{~kW}$ and reactive power is 0 Var. By comparing the simulation results of MP-DPTC and ST-DPTC, the following conclusions can be obtained: although both strategies can achieve the control purpose, the active power ripple, reactive power ripple, stator flux ripple, stator current ripple, and electromagnetic torque ripple of the MP-DPTC are smaller than those of ST-DPTC, and the stator current of the MP-DPTC is more similar to the sinusoidal waveform, furthermore the stability and robustness of the system are significantly improved.

\section{EXPERIMENT OF MARINE HYBRID DRIVE SYSTEM}

MP-DPTC is applied to marine hybrid drive system, TMS320F28335 chip is used as experiment platform in the system, $3 \mathrm{~kW}$ asynchronous motor is simulated as marine main diesel engines, 2.2kW PMSM is used as Shaft motor, these two motors are connected with power shaft of the ship through the magnetic powder clutch. Power mode can be switched by the magnetic powder clutch. The Normal converter and back-to-back inverter respectively control asynchronous motor and PMSM. All experimental devices of marine hybrid drive system are controlled by S7-200 PLC, and network switch control is achieved by bus RS485. The whole experimental device is shown in the Fig. 6.

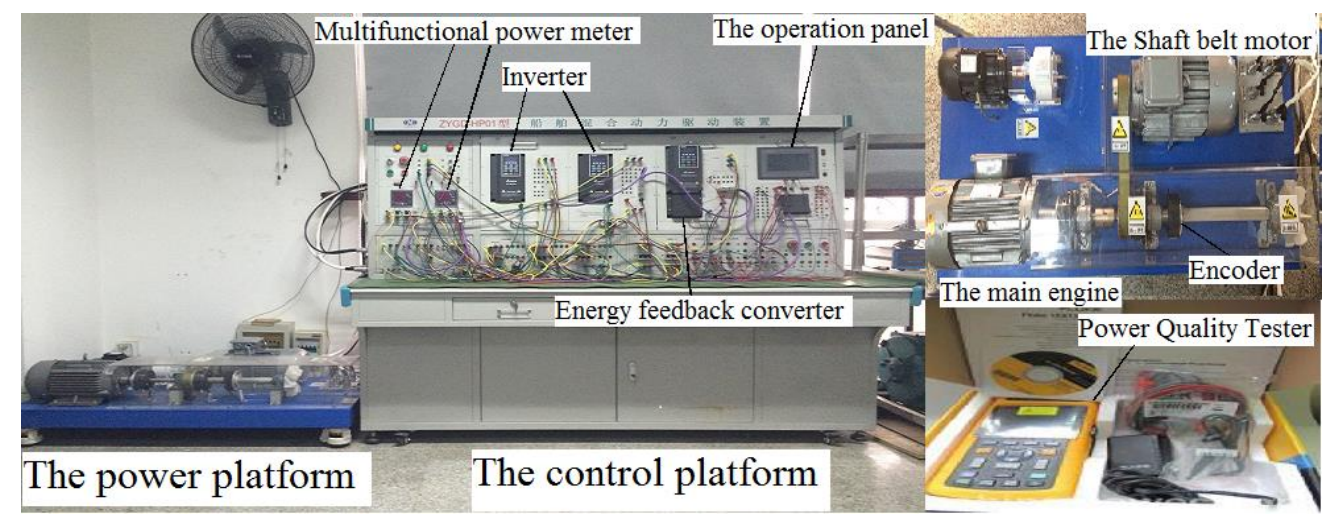

Fig. 6. The experiment platform

There are four working modes of the system, the main motor drives the ship separately; the shaft motor drives the ship separately; the main motor and shaft belt motor synchronously drive the ship; and the shaft motor works in the power generation mode when the main motor drives the ship. Owing to the output shaft diameter of two motors, the working frequency ratio of shaft motor and main motor is set to 1.017 when system works in the compound drive mode. The partial operating status of the system are given as follows:

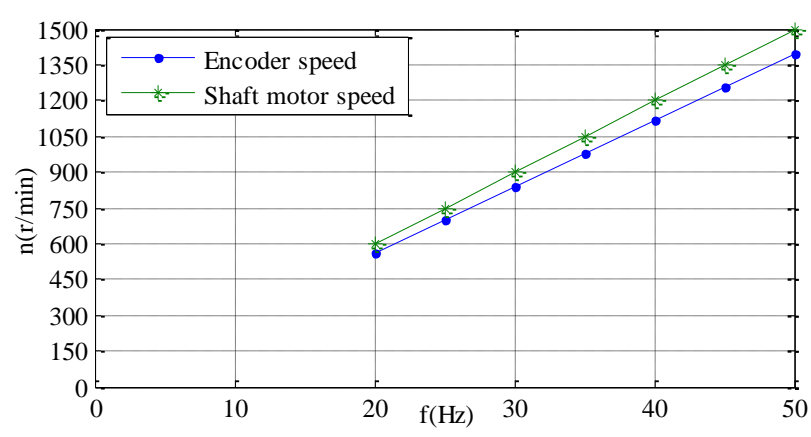

a. The operating speed at shaft motor drive 


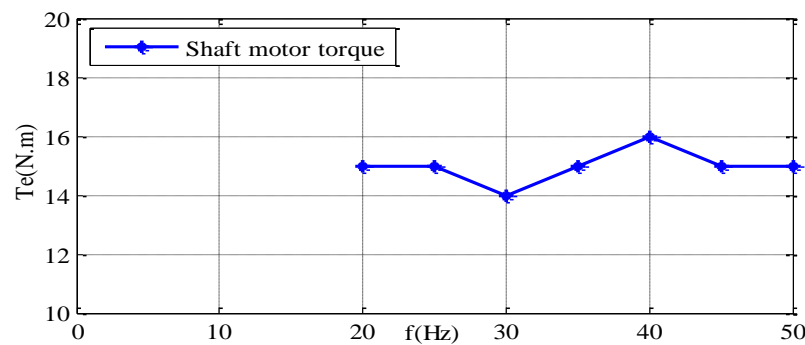

b. The operating torque at shaft motor drive

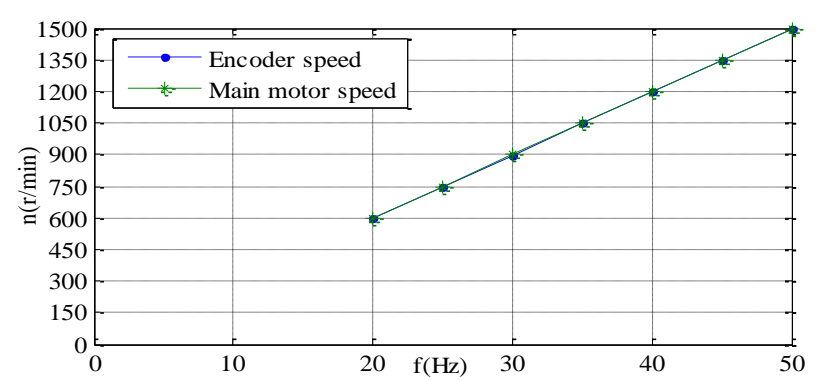

c. The operating speed at main motor drive

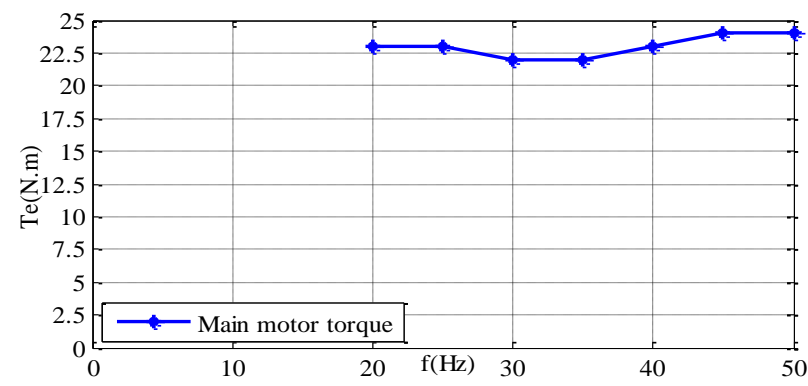

d. The operating torque at main motor drive

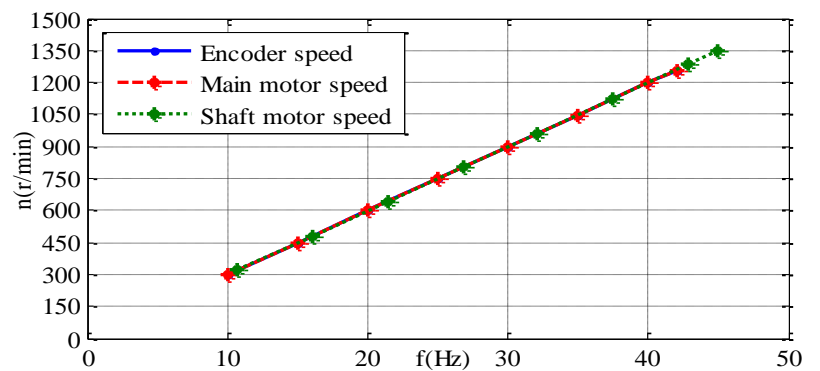

e. The operating speed at compound drive mode

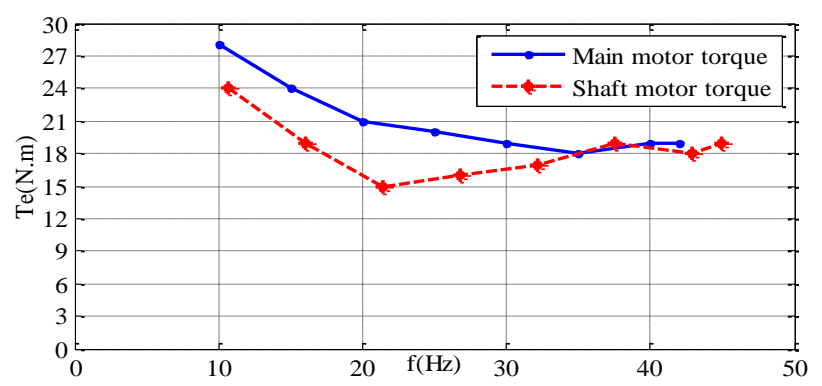

f. The operating torque at the compound drive mode

Fig. 7. The operating conditions of experimental platform
Based on Fig. a and Fig. b, It can be found that both motors can independently guarantee the normal operation of marine power system. At the compound drive mode, the operating conditions of the system are shown in fig. c. Under high speed, the torque of the two motors is relatively balanced, the main motor speed is consistent with the shaft motor speed after scaling, and the combined drive is basically realized. One of the operating conditions is selected to measure the electrical parameters. the system operating conditions are shown in Fig. 8. Note: All the test items in the figure are A-phase parameters. A and B in the figure respectively represent two channels of A phase.
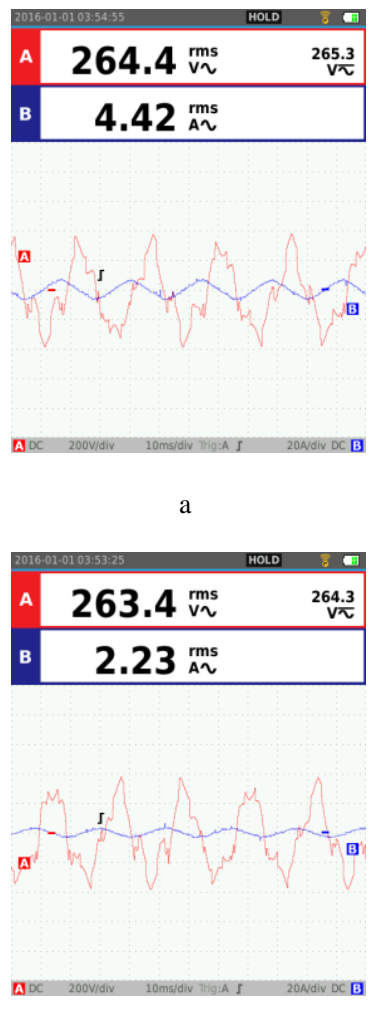

c
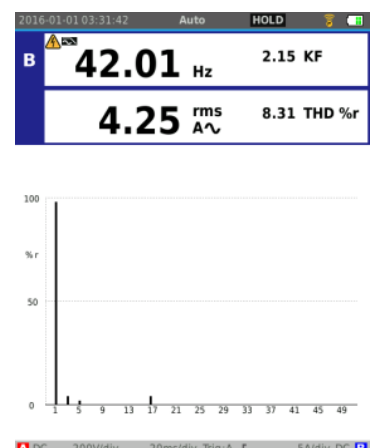

$\mathrm{b}$
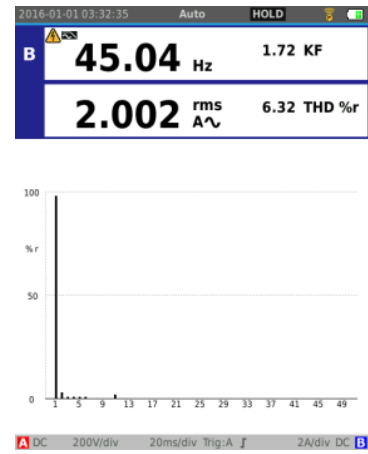

d
Fig. 8.The system conditions at the compound drive mode: (a) A phase voltage and A phase current of main motor, (b) A phase current spectrum of main motor, (c) A phase voltage and A phase current of shaft motor, (d) A phase current spectrum of shaft motor.

Fig. 8 shows system operating conditions: When the system works in the compound drive mode, A-phase current frequency of the main motor is equal to $42.01 \mathrm{~Hz}$, and the THD of the main motor current is equal to $8.31 \%$, A-phase current frequency of the shaft motor is equal to $45.04 \mathrm{~Hz}$, the THD of the shaft motor current is equal to $6.32 \%$. Obviously the THD of current and torque ripple are effectively reduced and the steady state performance of system is improved. 
In order to examine the bidirectional motor flow characteristic of the marine drive system when the system adopts the MP-DPTC, the main motor is set in electric mode and the shaft motor is set in power generation mode. In order to feedback the redundant energy of main motor, the working frequency ratio of shaft motor and main motor is set to 1 , and then the operating conditions of the system are shown in Fig. 9.

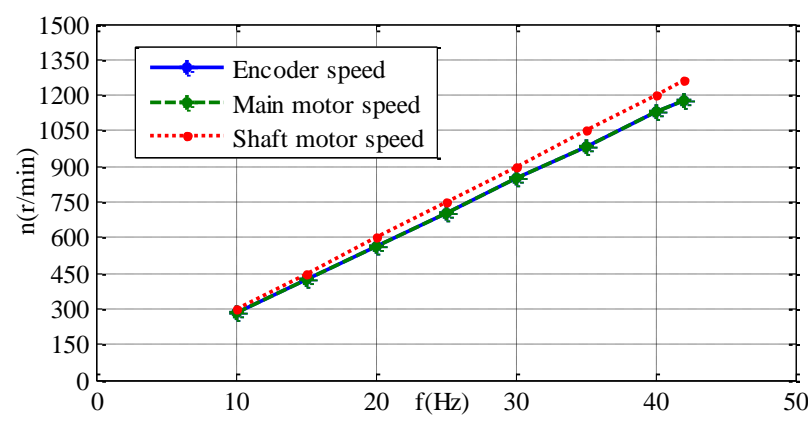

a

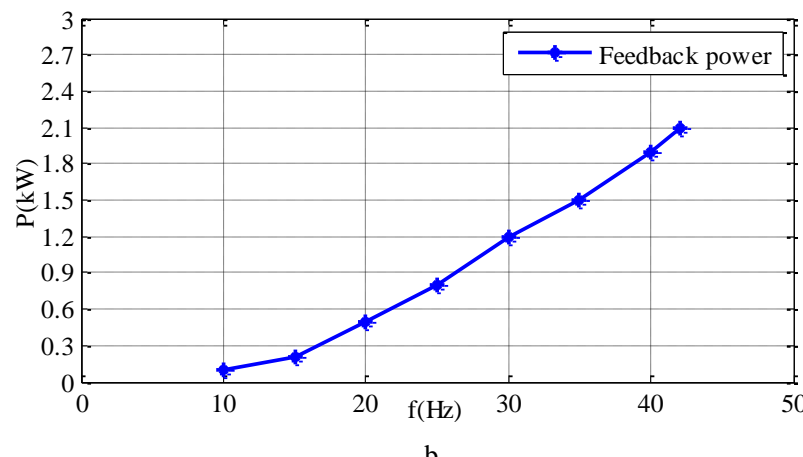

Fig. 9. The operating conditions at the power generation mode: (a) The speed results of experimental platform, (b) The feedback power of experimental platform

Based on Fig. 9, it is learned that the speed of main motor and shaft belt motor are basically consistent, and the system can realize the energy feedback. One of the operating conditions is selected to measure the electrical parameters. the system operating conditions are shown in Fig. 10 ${ }^{(16)}$.
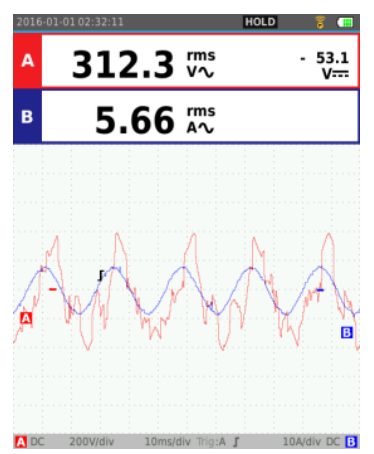

a
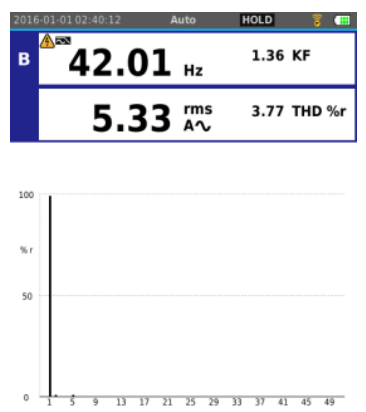

b

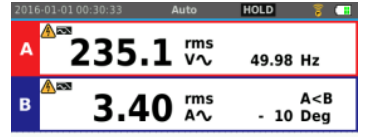

\begin{tabular}{|ll|}
\hline $234.9 \mathrm{rms}$ & $2.1 \mathrm{THD} \% \mathrm{r}$ \\
\hline $49.97 \mathrm{~Hz}$ & $0.98 \mathrm{KF}$ \\
\hline
\end{tabular}

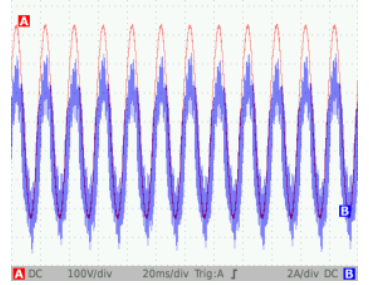

c
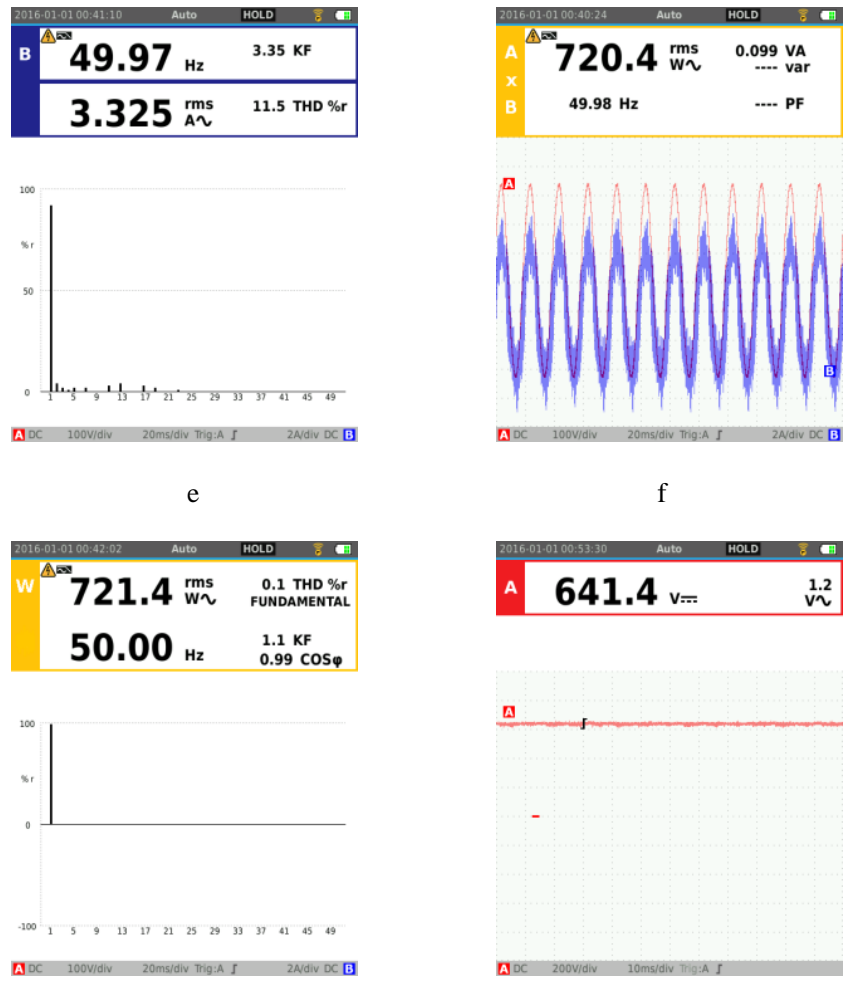

h

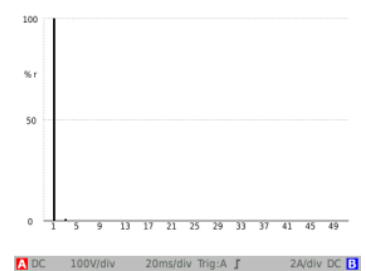

d

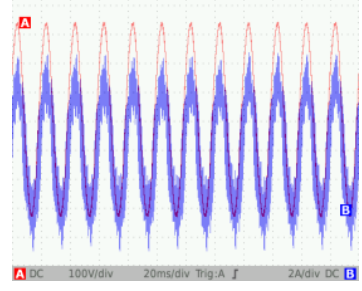

f

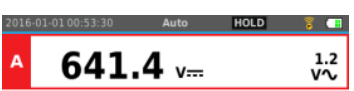

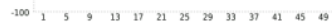

$\mathrm{g}$

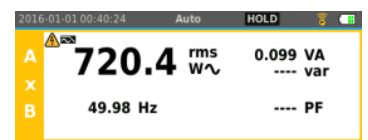

Fig. 10. The operating conditions under the shaft motor power generation mode: (a) A phase voltage and A phase current of shaft motor, (b)

A phase current spectrum of shaft motor, (c) The feedback voltage and current of A phase, (d) The spectrum of feedback A phase voltage, (e) The spectrum of feedback A phase current, (f) The feedback active power of A phase, (g) The spectrum of feedback A phase active power, (h) The DC bus voltage.

Fig. 10 shows that, under the power generation mode, the THD of the shaft motor A phase stator current reach $3.77 \%$, the stator current is approximately sinusoidal and the shaft motor runs smoothly. The system feeds back the motor to the grid by the back-to-back inverter, the feedback voltage frequency and current frequency of $\mathrm{A}$ phase are equal to $49.97 \mathrm{~Hz}$, the THD of voltage and current respectively reach $2.1 \%$ and $11.5 \%$,furthermore, the power factor reaches 0.99 
and the feedback active power ripple is ideal. The operating conditions show the system can feed back motor to the grid under the MP-DPTC strategy, the voltage of DC bus is stable, moreover,compared to the power grid of $50 \mathrm{~Hz}$, the frequency error of feedback voltage and current is $0.06 \%$. The feedback power quality and THD of feedback voltage reach the desired state. Although the THD of current needs to be improved, the design goal is basically realized.

\section{CONCLUSIONS}

The MP-DPTC is adopted in the marine hybrid drive system. In order to obtain the optimal voltage vector quickly, the complexity of the MP-DPC is simplified by an additional control algorithm. Similarly, the optimal duty cycle is introduced in the MP-DTC to reduce flux ripple and torque ripple. According to the comparison of simulation results between the ST-DPTC and MP-DPTC, the MP-DPTC effectively reduces the active power ripple, reactive power ripple, stator flux ripple, stator current ripple, and electromagnetic torque ripple of the system, furthermore, the stability and robustness of the system are significantly improved. Based on the experiment results: The operating mode of shaft motor is switched smoothly in the power generation and electric state. On the one hand when main motor is combined with shaft motor, the THD of the shaft motor current and the torque ripple of the motor are low, and on the other hand when the shaft motor is in power generation mode, the energy is fed back to the grid through the back-to-back inverter, and the frequency error of the feedback voltage and current is $0.06 \%$, furthermore the feedback active power ripple is effectively reduced and the value of power factor is 0.99 . All in all, the power quality of bidirectional flow energy and the drive ability are improved, the operational stability and the Switch stability of system are optimized at the same time. The excellent performance of the MP-DPTC is verified.

\section{REFERENCES}

[1] L Wang, “Researches on PMSM-driven System of Vessels" M.S.Thesis, Shanghai Maritime University, Shanghai, China, 2006: $1-12$.

[2] $\mathrm{B} \mathrm{Xu}$, "Technical research on harmonic mitigation in marine diesel-electric propulsion system” M.S. Thesis, Shanghai Jiao Tong University, Shanghai, China, 2014: 1-9.

[3] Z Lin, Huang S, Wan S. "A novel PWM rectifier control strategy applied on ship shaft synchronous generator converter system”
Proceedings of the CSEE. 2015, 36: 1117-1126.

[4] S Shao, Y Li. "Simulation Research of PWM Rectifier in Active Front End Drive” Journal of Shanghai Ship and Shipping Research Institute. 2011, 34: 43-47.

[5] X Li, "The Research of Control System of Synchronous Motor Applied in Ship Electric propulsion" Ph.D. Thesis, Harbin Engineering University, Harbin, China, 2010: 1-4 .

[6] C Qiu,S Huang,Z Lin,Z Wang. “A PWM Rectifier Control Strategy for Four-quadrant Cascade Converters Based on Complex Vector PI regulators” Proceedings of the CSEE. 2015, 35: 2804-2812.

[7] S Li, M Fairbank, C Johnson. "Artificial Neural Networks for Control of a Grid-Connected Rectifier/Inverter Under Disturbance Dynamic and Power Converter Switching Conditions” IEEE Trans. Neural Networks and Learning Systems. 2014, 25: 738-750.

[8] L Qi. "Research and application of permanent magnet synchronous motor via sliding mode control methods” Ph.D. Thesis, East China University of Science and Technology, Shanghai, China, 2013: 1-16.

[9] Z Lan, B Wan, T Tan. “A Novel Three-Vector Model Predictive Current Control for Permanent Magnet Synchronous Motor" Proceedings of the CSEE. 2018, 38: 243-249.

[10] J He, “Control and application of voltage source PWM converter" Huazhong University of Science\&Technology, Wuhan, China, 2012: $8-13$.

[11] W Zheng, Y Nie. “Application and Advantages of Rolls-Royce Hybrid Shaft Generator” Marine Electric\&Electronic Engineering. 2013, 33: 53-56.

[12] D Lu. "Control Strategies for Speed Control of Permanent Magnet Synchronous Motors” Ph.D. Thesis, Zhe Jiang University, Hangzhou, China, 2013: 15-21

[13] H Zhang, F Meng, Z Liang. "Direct power and torque integration control for energy feedback converter" Electric Machines and Control. 2013, 17: 19-26.

[14] E Wang, "Research on the motor control of four-quadrant converter" Ph.D. Thesis, Huazhong University of Science\&Technology, Wuhan, China, 2015: 37-54.

[15] L Alireza, A Mohammad. "Virtual Flux based Model-Predictive Direct Power Control of Three-Phase Three-Level NPC PWM Rectifier" In Proceedings of the Conference Record of the 2017 IEEE Power Electronics, Drive Systems \& Technologies Conference. 2017, 14: 172-177.

[16] X Qin. “Study on marine shaft motor control system based on model prediction” M.S. Thesis, Harbin Institute of Technology, Weihai, China, 2017: 23-64. 
[17] Y Zhang, W Xie. “Low Complexity Model Predictive Control-Single Vector-Based Approach”IEEE Trans. Power Electron. 2014,29: 5532 5541.

[18] X Wang, D Sun. “ Three-Vector-Based Low-Complexity Model Predictive Direct Power Control Strategy for Doubly Fed Induction Generators,” IEEE Trans. Power Electron. 2016, 19: 373-382.

[19] F Niu, B Wang, S Andrew. “Comparative Evaluation of Direct Torque Control Strategies for Permanent Magnet Synchronous Machines” IEEE Trans. Power Electron. 2015, 9: 1408-1424.

[20] K Shyu, J Lin, V Pham, M Yang, T Wang. “Minimum Torque Ripple Design for Direct Torque Control of Induction Motor Drives” IEEE Trans. Ind. Electron. 2010, 57: 3148 - 3156. 